\title{
Vaping Cardiovascular Health Risks: an Updated Umbrella Review
}

\author{
Mariangela Peruzzi ${ }^{1,2} \cdot$ Giuseppe Biondi-Zoccai $^{1,2}$ (D) $\cdot$ Roberto Carnevale $^{1,2} \cdot$ Elena Cavarretta $^{1,2} \cdot$ Giacomo Frati $^{1,3}$. \\ Francesco Versaci ${ }^{4}$
}

Published online: 16 June 2020

(C) Springer Science+Business Media, LLC, part of Springer Nature 2020

\begin{abstract}
Purpose of Review Modified risk products (MRP) such as electronic vaping cigarettes (EVC) and heat-not-burn cigarettes (HNBC) are alternatives to traditional combustion cigarettes (TCC) with an expanding consumer base. Yet, their cardiovascular health risks are still unclear. We aimed to summarize the evidence base on this topic by conducting an updated umbrella review. Recent Findings We identified 7 systematic reviews, totaling 183 studies and reports, ranging from in vitro and in animal studies to clinical studies in apparently healthy volunteers and patients at risk of cardiovascular disease. Overall, acute EVC use was associated with several toxic effects at molecular, cellular, tissue, organ, and system level. In addition, EVC impacted adversely on blood pressure (BP) management, caused tachycardia, and worsened arterial stiffness. Finally, EVC use was associated with an increased risk of adverse clinical events, including atrial fibrillation and myocardial infarction, even if the causal link is still debated. Most reviews highlighted that the detrimental impact of EVC was of lesser magnitude of that of TCC. In addition, the differential impact of liquids and nicotine was not clearly disentangled. Finally, no review included studies on HNBC.

Summary The present umbrella review suggests that EVC, and likely HNBC, despite clearly causing an increase in overall cardiovascular risk, may represent a temporary lesser evil than TCC in a risk-reduction or risk-modification strategy, aiming for eventual abstinence from all tobacco or nicotine products.
\end{abstract}

Keywords Cardiovascular disease $\cdot$ Electronic cigarette $\cdot$ Electronic vaping cigarette $\cdot$ Heat-not-burn cigarette $\cdot$ Smoking

Giving up smoking is the easiest thing in the world. I know because I've done it thousands of times. Mark Twain

This article is part of the Topical collection on Cardiovascular Care

Giuseppe Biondi-Zoccai

giuseppe.biondizoccai@uniroma1.it

1 Department of Medical-Surgical Sciences and Biotechnology, Sapienza University of Rome, Corso della Repubblica 79, 04100 Latina, Italy

2 Mediterranea Cardiocentro, Naples, Italy

3 IRCCS NEUROMED, Pozzilli, Italy

4 Division of Cardiology, S. Maria Goretti Hospital, Latina, Italy

\section{Introduction}

Smoking represents one of the leading causes of preventable morbidity and mortality worldwide, causing a plethora of adverse medical conditions, including coronary artery disease, stroke, chronic obstructive pulmonary disease, and cancer, and its detrimental effects impact also on passive smokers $[1 \bullet, 2-5]$. Even in the current coronavirus-associated disease 2019 (COVID-19) pandemic, smokers, especially the elderly, appear to have an increased risk of getting infected, progressing toward severely symptomatic disease, and dying due to severe acute respiratory syndrome-coronavirus-2 (SARS-CoV-2) infection [6-9].

Abstinence is easy to preach but harder to achieve, and several strategies have been proposed to ensure smokers can discontinue and abstain from their habit, ranging from telemedicine, nicotine replacement therapy, varenicline, and bupropion $[10 \bullet \cdot$. Most recently, novel forms of smoking have been developed, which differ from traditional combustion cigarettes (TCC) as smoking is not due to combustion but vaporization of nicotine-containing liquids, i.e., electronic vaping cigarettes (EVC), or heating of tobacco products without combustion, 
i.e. heat-not-burn cigarettes (HNBC) [11-12]. Collectively, these alternative ways to smoke are called modified risk products (MRP) or, more optimistically, reduced risk products (RRP) [13, 14••, 15-17].

Substantial evidence continues to accrue on MRP, including results of randomized controlled trials (RCT), and several systematic reviews have already been published on this topic $[18 \cdot \bullet$. However, the interplay between MRP, cardiovascular physiology, and cardiovascular disease is still uncertain, with conflicting results provided by different scholarly sources [19]. We thus aimed at conducting an updated umbrella review of systematic reviews on the cardiovascular effects, in terms of both pathophysiology and symptomatic disease, of $\mathrm{EVC}$ and $\mathrm{HNBC}\left[20^{\bullet}\right]$.

\section{Methods}

In keeping with prior similar projects led by our group, this work was designed as an umbrella review (i.e., overview of systematic reviews) following established recommendations for evidence synthesis [20•,21-22]. Specifically, we searched PubMed in order to find pertinent systematic reviews on the cardiovascular safety of MPR using the following string: (vaping OR vapes OR e-cigarette OR ecigarette OR (electronic AND cigarette) OR iqos OR juul) AND (heart OR cardiac OR coronary OR vascular OR venous OR cardiovascular OR artery OR arterial OR myocardial OR thrombosis OR atherosclerosis OR atherothrombosis) AND systematic[sb], restricting our search to studies published until May 5, 2020. Citations were first screened at the title/abstract level. Then, full texts were sought if potentially pertinent. We extracted salient features of included reviews, as well as corresponding original studies when appropriate. Review quality was appraised using the Oxman-Guyatt index [20•].

\section{Recent Findings}

From 36 citations, we appraised in detail 17 articles, eventually including 7 systematic reviews, totaling 183 studies and reports (Tables 1, 2 and 3) [18・•, 19, 23-28, 29•]. Specifically, Tzortzi et al. overviewed case reports on EVC-related injury reported in several databases including the leading US Center for Disease Control [29•]. From a total of 133 publications, no specific cardiac event was reported, but chest pain was relatively common in such compiled series of cases $(22 \%)$. Hua and Talbot screened several databases looking for case reports of adverse events associated with EVC use, retrieving two cases (a case of acute myocardial infarction in a young man and a case of atrial fibrillation in an elderly woman) [24]. In both cases reported in this hypothesis-generating systematic review, nicotinecontaining EVC had been used.

Farsalinos and Polosa conducted a systematic review on several different generations of EVC focusing on their comparison versus TCC and nicotine gums, the impact of nicotine, and the risk of active as well as passive smoking [18••]. In particular, they synthesized evidence from 97 different reports, including several chemical studies, toxicological studies, and clinical trials. They concluded that, despite evident safety issues, including the presence of many toxic agents with established multidimensional risk (e.g., acetaldehyde, acrolein, aluminum, amino-tandalafil, copper, diethylene glycol, formaldehyde, iron, lead, nickel, particulate matter, rimonambant, and silica), EVC represent an appealing alternative to TCC in a RRP strategy. In terms of hazards, they highlighted the risk of tachycardia and hypertension, as well as impaired left anterior descending flow reserve, even if it remained unclear whether these effects depended mainly on nicotine. Interestingly, this old review was promising but limited by incomplete reporting and lack of quantitative synthesis.

Garcia and colleagues performed a systematic review and meta-analysis on the effects of EVC on blood pressure (BP), heart rate (HR), and heart rate variability (HRV), pooling data from 19 studies, and using largely explicit and valid methods [23]. They concluded that EVC are associated with acute increases in systolic blood pressure (SBP), diastolic blood pressure (DBP), and HR, and changes in HRV typical of sympathetic prevalence over vagal activity, even if mostly explained by nicotine exposure. Notably, chronic use of EVC still had adverse effects on HRV, but effects on BP and HR were much more diluted, potentially suggesting time-dependent adaptation.

Kennedy and colleagues reviewed several experimental and clinical studies on the cardiovascular safety of EVC, highlighting that they may cause oxidative stress, cardiomyocyte dysfunction and mutagenesis, vascular inflammation, endothelial dysfunction, vasospasm, complement deposition, platelet aggregation, adhesion, and activation, with hypertension, tachycardia, arterial stiffening, atherosclerosis and thrombotic risk, albeit less intensely than TCC [25]. Most importantly, they suggested that studies with conflicts of interest were less likely to report adverse events.

Skotsimara and colleagues reviewed 26 studies, ranging from preclinical to clinical ones, and then performed a formal meta-analysis of 14 trials [28]. Overall, they identified the following as main signs of detrimental effects of EVC: cytotoxicity, oxidative stress, endothelial dysfunction, BP, HR, arterial stiffness, and myocardial infarction. Notably, most of these effects were heterogeneous and quantitatively less intense than those associated with TCC.

Finally, Riley et al. conducted a systematic review originally focused on the interplay between hormonal 
Table 1 Systematic reviews screened for the present umbrella review

\begin{tabular}{lllll}
\hline First author (year) & PubMed ID & Studies/reports included & Screening result & Reason for exclusion \\
\hline Boffetta (2009) & 19690343 & 11 & Excluded & Focus on smokeless, snuff, or spit tobacco \\
Cardenas (2019) & 1582941 & 0 & Excluded & Focus on pregnancy \\
Critchley (2004) & 12728167 & 95 & Excluded & Focus on smokeless, snuff, or spit tobacco \\
Farsalinos (2014) & 25083263 & 97 & Included & - \\
Farsalinos (2018) & 29375395 & 32 & Excluded & Focus on carbonyl emissions \\
Garcia (2020) & 32219640 & 19 & Included & - \\
Hua (2016) & 27413679 & 2 & Included & - \\
Kalkhoran (2016) & 26776875 & 38 & Excluded & Focus on smoking cessation \\
Kennedy (2019) & 31344384 & 24 & Included & - \\
Kozak (2020) & 32011186 & 12 & Excluded & Focus on schizophrenia \\
Leite (2018) & 29656920 & 28 & Excluded & Focus on periodontitis \\
Rahman (2015) & 25822251 & 6 & Excluded & Focus on smoking cessation \\
Riley (2016) & 26546021 & 13 & Included & - \\
Rostron (2018) & 30364426 & 25 & Excluded & Focus on smokeless tobacco \\
Skotsimara (2019) & 30823865 & 26 & Included & - \\
Tzortzi (2020) & 32230711 & 2 & Included & - \\
Vidyasagaran (2016) & 27256827 & 20 & Excluded & Focus on smokeless tobacco \\
\hline
\end{tabular}

contraception, EVC, and cardiovascular risk [19]. No study explicitly focused on hormonal contraception was retrieved, and thus they expanded their analysis to the pathophysiologic link between EVC and cardiovascular outcomes. After including a total of 13 studies they concluded that EVC significantly impact of BP and HR, and may be associated with an increased risk of myocardial infarction.

\section{Implications}

Our umbrella review, poignantly synthesizing the evidence accrued so far from in vitro, in animal, in human volunteers, healthy subjects, and patients on the cardiovascular risk associated with EVC use, either acute or chronic, shows that data are expanding progressively, but several conclusions can already be made on the

Table 2 Main features of included systematic reviews

\begin{tabular}{|c|c|c|c|}
\hline $\begin{array}{l}\text { First author } \\
\text { (year) }\end{array}$ & Exposure/intervention & Comparison & Findings \\
\hline $\begin{array}{l}\text { Farsalinos } \\
\quad(2014)\end{array}$ & $\begin{array}{l}\text { EVC with nicotine, EVC without } \\
\text { nicotine }\end{array}$ & $\begin{array}{l}\text { Nihil, NRT, } \\
\text { sham, TCC }\end{array}$ & $\begin{array}{l}\text { EVC are a less harmful alternative to TCC and significant health benefits are expected } \\
\text { in smokers who switch from TCC to EVC. }\end{array}$ \\
\hline $\begin{array}{l}\text { Garcia } \\
\quad(2020)\end{array}$ & $\begin{array}{l}\text { EVC with nicotine, EVC without } \\
\text { nicotine }\end{array}$ & $\begin{array}{l}\text { Nihil, sham, } \\
\text { TCC }\end{array}$ & $\begin{array}{l}\text { EVC acutely increase HR and BP but less than TCC. } \\
\text { Nicotine but not non-nicotine constituents in EVC aerosol were responsible for the } \\
\text { sympathoexcitatory effects. EVC chronically lower HRV }\end{array}$ \\
\hline Hua (2016) & EVC with nicotine & NA & $\begin{array}{l}\text { EVC use was associated with atrial fibrillation or myocardial infarction in two case } \\
\text { reports. }\end{array}$ \\
\hline $\begin{array}{r}\text { Kennedy } \\
(2019)\end{array}$ & $\begin{array}{l}\text { EVC with nicotine, EVC without } \\
\text { nicotine }\end{array}$ & $\begin{array}{l}\text { Nihil, sham, } \\
\text { TCC }\end{array}$ & $\begin{array}{l}\text { EVC increased sympathetic nerve activity, platelet hemostatic processes, } \\
\text { reactive oxygen species production and endothelial dysfunction. } \\
\text { Notably, studies with conflicts of interest or median-high risk of bias were less } \\
\text { likely to identify potentially harmful effects. }\end{array}$ \\
\hline $\begin{array}{l}\text { Riley } \\
\text { (2016) }\end{array}$ & $\begin{array}{l}\text { EVC with nicotine, EVC without } \\
\text { nicotine }\end{array}$ & $\begin{array}{l}\text { Nihil, sham, } \\
\text { TCC }\end{array}$ & $\begin{array}{l}\text { EVC may increase HR and BP less than TCC. } \\
\text { CV events are rare among EVC users in the general population. }\end{array}$ \\
\hline $\begin{array}{c}\text { Skotsimara } \\
\text { (2019) }\end{array}$ & EVC with nicotine & $\begin{array}{l}\text { Nihil, sham, } \\
\text { TCC }\end{array}$ & $\begin{array}{l}\text { EVC have detrimental effects on endothelial function, arterial stiffness, } \\
\text { and risk of coronary events, and also increase HR, SBP, and DBP. } \\
\text { However, their impact on HR, SBP, and DBP is less severe than TCC. }\end{array}$ \\
\hline $\begin{array}{l}\text { Tzortzi } \\
\quad(2020)\end{array}$ & $\begin{array}{l}\text { EVC with nicotine, EVC with } \\
\text { cannabinoid and nicotine }\end{array}$ & NA & EVC use was associated with acute coronary syndromes in two young patients. \\
\hline
\end{tabular}

$B P$, blood pressure; $D B P$, diastolic blood pressure; $E V C$, electronic vaping cigarette; $H R$, heart rate; $N A$, not applicable; $N R T$, nicotine replacement therapy; $T C C$, traditional combustion cigarette; $S B P$, systolic blood pressure 
Table 3 Quality features of included systematic reviews

\begin{tabular}{|c|c|c|c|c|c|c|c|c|c|}
\hline $\begin{array}{l}\text { First author } \\
\text { (year) }\end{array}$ & $\begin{array}{l}\text { Explicit } \\
\text { search } \\
\text { methods }\end{array}$ & $\begin{array}{l}\text { Comprehensive } \\
\text { search }\end{array}$ & $\begin{array}{l}\text { Explicit } \\
\text { selection } \\
\text { criteria }\end{array}$ & $\begin{array}{l}\text { Appropriate } \\
\text { selection }\end{array}$ & $\begin{array}{l}\text { Explicit } \\
\text { validity } \\
\text { criteria }\end{array}$ & $\begin{array}{l}\text { Appropriate } \\
\text { validity } \\
\text { assessment }\end{array}$ & $\begin{array}{l}\text { Explicit } \\
\text { analysis } \\
\text { methods }\end{array}$ & $\begin{array}{l}\text { Appropriate } \\
\text { analysis } \\
\text { methods }\end{array}$ & $\begin{array}{l}\text { Appropriate } \\
\text { interpretation }\end{array}$ \\
\hline $\begin{array}{l}\text { Farsalinos } \\
\text { (2014) }\end{array}$ & No & No & No & No & No & No & NA & NA & NA \\
\hline $\begin{array}{l}\text { Garcia } \\
\qquad(2020)\end{array}$ & Yes & Yes & Yes & Yes & No & No & Yes & Yes & Yes \\
\hline Hua (2016) & Yes & Yes & Yes & Yes & No & No & NA & NA & Yes \\
\hline $\begin{array}{r}\text { Kennedy } \\
(2019)\end{array}$ & Yes & Yes & Yes & Yes & Yes & Yes & NA & NA & Yes \\
\hline $\begin{array}{l}\text { Riley } \\
\text { (2016) }\end{array}$ & Yes & Yes & Yes & Yes & Yes & Yes & NA & NA & Yes \\
\hline $\begin{array}{l}\text { Skotsimara } \\
\text { (2019) }\end{array}$ & Yes & Yes & Yes & Yes & Yes & Yes & Yes & Yes & Yes \\
\hline $\begin{array}{l}\text { Tzortzi } \\
\text { (2020) }\end{array}$ & Yes & Yes & Yes & Yes & No & No & NA & NA & NA \\
\hline
\end{tabular}

$N A$, not applicable

multidimensional hazards of EVC (Fig. 1, Table 4) [30••, 31]. First, acute EVC use is associated with several toxic effects at molecular (e.g., DNA), cellular, tissue, organ, and system level $[25,32]$. For instance, oxidative stress, cytotoxicity, and cardiomyocyte dysfunction are established effects of EVC [33]. Second, EVC impact adversely on BP management, cause tachycardia, and worsen arterial stiffness [19, 34]. Third, EVC use has been associated with an increased risk of adverse clinical events, including atrial fibrillation and myocardial infarction, even if the causal link is still debated [24, 35]. Yet, most reviews highlighted that the detrimental impact of EVC was of lesser magnitude of that of TCC. In addition, the differential impact of liquids and nicotine was not clearly disentangled.

Overall, these findings confirm prior reports and support further research on the topic of cardiovascular safety of EVC. Several avenues for research are worth exploring. For instance, translational studies on the precise cellular mechanisms involved in EVC toxicity are needed, exploring for instance microRNA, inflammatory cascade, autophagy, apoptosis, and regeneration [36-38]. Observational studies on large samples are needed to accurately gauge the short and long-term risks of EVC in apparently healthy subjects and in patients with cardiovascular disease [39]. In addition, randomized trials, from small-sample speculative ones to large pragmatic studies, are direly needed to ensure that the place of EVC in current clinical practice is correctly defined [40]. Indeed, our premise is that EVC should be considered as an over-the-counter medical intervention suitable to support chronic smokers in their journey to eventual cessation. Accordingly, only a comprehensive evidence platform, hopefully summarized in a formal network meta-analysis, will be able to precisely define the place and role, if any, of EVC in a comprehensive approach aiming at smoking cessation and harm minimization [41]. Pragmatically, and based on our personal and professional experience, we may suggest a stepwise use of EVC and $\mathrm{HNBC}$ with the eventual aim of total and

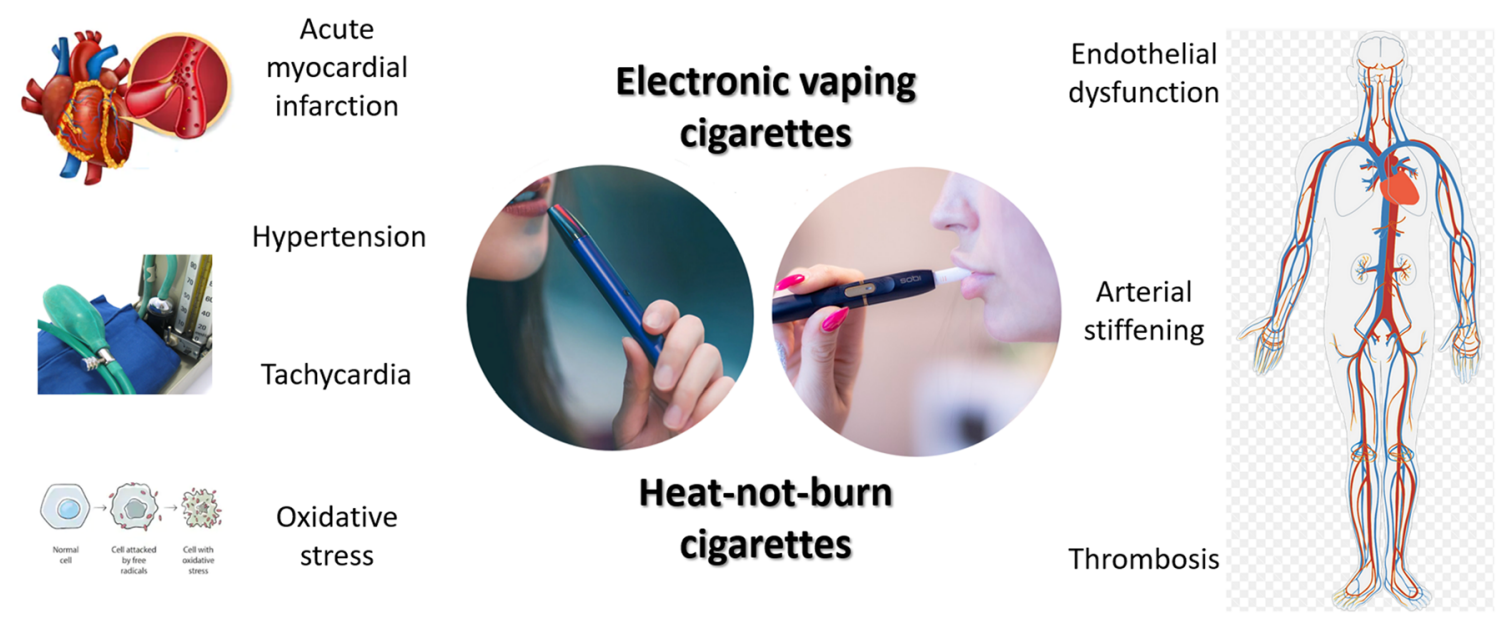

Fig. 1 Key adverse cardiovascular effects of electronic vaping cigarettes and heat-not-burn cigarettes 
Table 4 Key adverse cardiovascular effects and potential clinical impact of electronic vaping cigarettes and heat-not-burn cigarettes

\begin{tabular}{ll}
\hline Effect & Potential impact \\
\hline$\uparrow$ Arrhythmic risk & $\begin{array}{c}\text { Lipothymia, loss of consciousness, } \\
\text { syncope, weakness }\end{array}$ \\
$\uparrow$ Arterial stiffness & Ischemia \\
$\uparrow$ Blood pressure & $\begin{array}{c}\text { Atherothrombosis, myocardial } \\
\text { hypertrophy, renal failure }\end{array}$ \\
$\uparrow$ Heart rate & Myocardial ischemia \\
$\uparrow$ Oxidative stress & Atherothrombosis, diabetes \\
$\uparrow$ Platelet aggregation & Atherothrombosis \\
$\downarrow$ Cardiomyocyte function & Decline in left ventricular systolic \\
& function \\
$\downarrow$ Flow-mediated dilation & Ischemia \\
$\downarrow$ Left anterior descending & Myocardial ischemia \\
flow reserve & \\
$\downarrow$ Vasodilation & Systemic hypertension \\
\hline
\end{tabular}

continued abstinence (Fig. 2). Yet, practitioners should be aware of the potential interactions between MRP and pharmacologic therapy in patients with or at risk of cardiovascular disease, ranging from atherothrombosis to heart failure and valvular heart disease [42-46], as indeed it is plausible that many of the adverse cardiovascular effects of MRP depend on nicotine, thus raising the evident risk of cumulative toxicity if NRT and MRP are inadvertently combined.

\section{Limitations}

This umbrella review has several drawbacks, on top of those typical of this research design [20 $]$. First, studies and reviews discussed hereby are mostly of small size and limited followup, and often focus on apparently healthy subjects. Second, data on long-term pulmonary and cancer risk are absent, but this cannot be considered proof of absence of oncologic risk, as only longitudinal studies will be able to inform on this safety dimension. Another elephant in the room is the lack of comprehensive data on HNBC, which are a mainstay in the MRP arena, and can be considered for some aspects as safe or safer than EVC, and for others worse (e.g., because of small but measurable combustion) [47•]. Accordingly, we expect that additional research synthesis efforts will be needed in the future, including updated umbrella reviews.

\section{Future Directions}

The information accrued in this umbrella review, coherently showing multidimensional adverse effects of HNBC and EVC, highlights the evident risk of adverse cardiovascular events associated with MRP. Accordingly, further restrictions to their usage could be considered, including equating them to over-the-counter or even prescription drugs. Indeed, the best perspective is considering $\mathrm{HNBC}$ and EVC as another

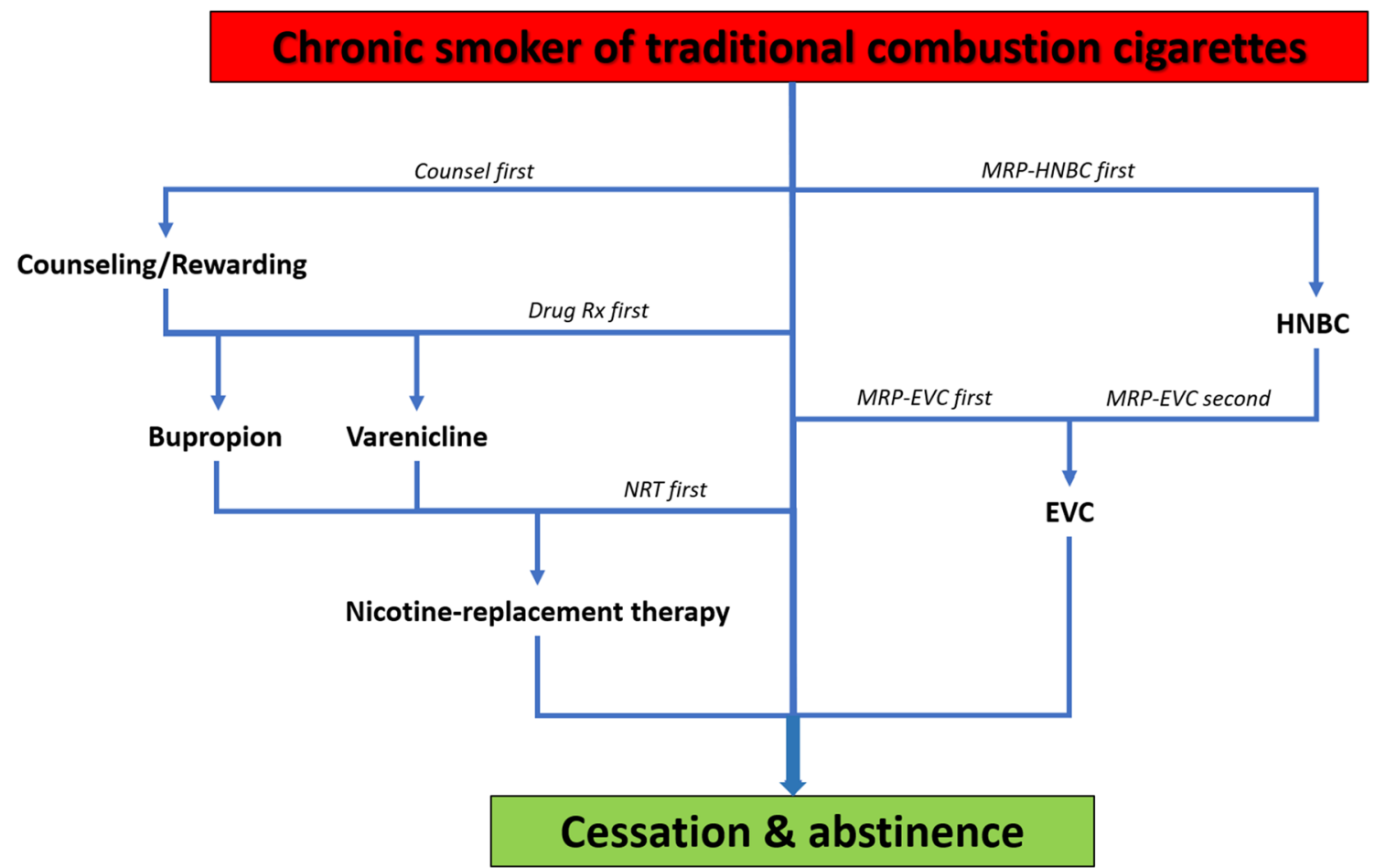

Fig. 2 Potential algorithm to exploit modified risk products (MRP) such as electronic vaping cigarettes (EVC) and heat-not-burn cigarettes (HNBC), on top of counseling, drug therapy, and nicotine replacement therapy (NRT), to promote smoking cessation and abstinence 
management strategy to promote smoking cessation and maintain abstinence (Fig. 2).

Moreover, their usage should be monitored, minimized in intensity and duration, aiming for clear timelines to switch from $\mathrm{HNBC}$ to EVC and then stop them altogether if a HNBC-first approach is chosen, or instead having a goal of EVC usage followed by cessation if an EVC-first approach is adopted. An apparently banal but potentially useful framework could indeed be considering MRP as a novel and more palatable NRT, maintaining many of the rituals of TCC without the abundance of combustion byproducts.

Nonetheless, dedicated large-scale and pragmatic randomized trials are needed to test the above strategy before recommending it to individuals and patients at large.

\section{Conclusions}

The present umbrella review suggests that EVC, despite clearly causing an increase in overall cardiovascular risk, may represent a temporary lesser evil than TCC in a risk-reduction or risk-modification strategy, aiming for eventual abstinence from all tobacco or nicotine products.

\section{Compliance with Ethical Standards}

Conflict of Interest The authors declare that they have no conflict of interest.

Human and Animal Rights and Informed Consent This article does not contain any studies with human or animal subjects performed by any of the authors.

\section{References}

Papers of particular interest, published recently, have been highlighted as:

- Of importance

-• Of major importance

1. Britton J, Edwards R. Tobacco smoking, harm reduction, and nicotine product regulation. Lancet. 2008;371:441-5 Comprehensive perspective on burden of smoking and strategies to reduce it.

2. Nicol P, Xhepa E, Bozhko D, Joner M. Neoatherosclerosis: from basic principles to intravascular imaging. Minerva Cardioangiol. 2018;66:292-300.

3. Protano C, Manigrasso M, Cammalleri V, Biondi Zoccai G, Frati $\mathrm{G}$, Avino $\mathrm{P}$, et al. Impact of electronic alternatives to tobacco cigarettes on indoor air particular matter Levels. Int J Environ Res Public Health. 2020;17:E2947.

4. Aronow WS. Implications of the new 2017 American College of Cardiology/American Heart Association guidelines for hypertension. Minerva Cardioangiol. 2019;67:399-410.

5. Pauli N, Kuligowska A, Krzystolik A, Dziedziejko V, Safranow K, Rać M, et al. The circulating VEGF is only marginally associated with an increased risk for atherosclerosis. Minerva Cardioangiol. 2020. https://doi.org/10.23736/S0026-4725.20.04995-6.

6. Driggin E, Madhavan MV, Bikdeli B, Chuich T, Laracy J, BiondiZoccai G, et al. Cardiovascular considerations for patients, health care workers, and health systems during the COVID-19 pandemic. J Am Coll Cardiol. 2020;75:2352-71.

7. Biondi-Zoccai G, Landoni G, Carnevale R, Cavarretta E, Sciarretta S, Frati G. SARS-CoV-2 and COVID-19: facing the pandemic together as citizens and cardiovascular practitioners. Minerva Cardioangiol. 2020;68:61-4.

8. Saglietto A, D'Ascenzo F, Zoccai GB, De Ferrari GM. COVID-19 in Europe: the Italian lesson. Lancet. 2020;395:1110-1.

9. Marullo AG, Cavarretta E, Biondi-Zoccai G, Mancone M, Peruzzi $\mathrm{M}$, Piscioneri $\mathrm{F}$, et al. Extracorporeal membrane oxygenation for critically ill patients with coronavirus-associated disease 2019: an updated perspective of the European experience. Minerva Cardioangiol. 2020. https://doi.org/10.23736/S0026-4725.20. 05328-1.

10.• Suissa K, Larivière J, Eisenberg MJ, Eberg M, Gore GC, Grad R, et al. Efficacy and safety of smoking cessation interventions in patients with cardiovascular disease: a network meta-analysis of randomized controlled trials. Circ Cardiovasc Qual Outcomes. 2017;10:e002458 Detailed meta-analysis comparing different smoking cessations interventions in patients with cardiovascular disease.

11. Biondi-Zoccai G, Sciarretta S, Carnevale R, Peruzzi M, Frati G. Cardiovascular benefits of switching from tobacco to electronic cigarettes. J Am Coll Cardiol. 2020;75:1613.

12. Theron AJ, Feldman C, Richards GA, Tintinger GR, Anderson R. Electronic cigarettes: where to from here? J Thorac Dis. 2019;11: 5572-85.

13. Carnevale R, Sciarretta S, Violi F, Nocella C, Loffredo L, Perri L, et al. Acute impact of tobacco vs electronic cigarette smoking on oxidative stress and vascular function. Chest. 2016;150:606-12.

14.• Biondi-Zoccai G, Sciarretta S, Bullen C, Nocella C, Violi F, Loffredo L, et al. Acute effects of heat-not-burn, electronic vaping, and traditional tobacco combustion cigarettes: the Sapienza University of Rome-Vascular Assessment of Proatherosclerotic Effects of Smoking ( SUR - VAPES ) 2 randomized trial. J Am Heart Assoc. 2019;8(6):e010455 Randomized trial comparing traditional cigarettes, electronic vaping cigarettes, and heatnot-burn cigarettes in terms of acute cardiovascular safety.

15. Frati G, Carnevale R, Nocella C, Peruzzi M, Marullo AGM, De Falco E, et al. Profiling the acute effects of modified risk products: evidence from the SUR-VAPES (Sapienza University of RomeVascular Assessment of Proatherosclerotic Effects of Smoking) cluster study. Curr Atheroscler Rep. 2020;22:8.

16. Nocella C, Biondi-Zoccai G, Sciarretta S, Peruzzi M, Pagano F, Loffredo L, et al. Impact of tobacco versus electronic cigarette smoking on platelet function. Am J Cardiol. 2018;122:1477-81.

17. Mastrangeli S, Carnevale R, Cavarretta E, Sciarretta S, Peruzzi M, Marullo AGM, et al. Predictors of oxidative stress and vascular function in an experimental study of tobacco versus electronic cigarettes: a post hoc analysis of the SUR-VAPES 1 Study. Tob Induc Dis. 2018;16:18.

18.• Farsalinos KE, Polosa R. Safety evaluation and risk assessment of electronic cigarettes as tobacco cigarette substitutes: a systematic review. Ther Adv Drug Saf. 2014;5:67-86 Comprehensive review on dozens of basic, translational, and clinical reports appraising the safety profile of electronic cigarettes.

19. Riley HE, Berry-Bibee E, England LJ, Jamieson DJ, Marchbanks PA, Curtis KM. Hormonal contraception among electronic cigarette users and cardiovascular risk: a systematic review. Contraception. 2016;93:190-208.

20. Biondi-Zoccai G, editor. Umbrella reviews: evidence synthesis with overviews of reviews and meta-epidemiologic studies. 
Cham: Springer Nature; 2016. Comprehensive methodological guidance for readers and writers of umbrella reviews.

21. Biondi-Zoccai G, Antonazzo B, Giordano A, Versaci F, Frati G, Ronzoni S, et al. Oral antiplatelet therapy in the elderly undergoing percutaneous coronary intervention: an umbrella review. J Thorac Dis. 2020;12:1656-64.

22. Antonazzo B, Biondi-Zoccai G, Marullo AGM, Frati G, Ronzoni S, Chiariello GA, et al. Transcatheter aortic valve implantation in the elderly: an umbrella review. Vessel Plus. 2020;4:3.

23. Garcia PD, Gornbein JA, Middlekauff HR. Cardiovascular autonomic effects of electronic cigarette use: a systematic review. Clin Auton Res. 2020. https://doi.org/10.1007/s10286-020-00683-4.

24. Hua M, Talbot P. Potential health effects of electronic cigarettes: a systematic review of case reports. Prev Med Rep. 2016;4:169-78.

25. Kennedy CD, van Schalkwyk MCI, McKee M, Pisinger C. The cardiovascular effects of electronic cigarettes: a systematic review of experimental studies. Prev Med. 2019;127:105770.

26. Kalkhoran S, Glantz SA. E-cigarettes and smoking cessation in real-world and clinical settings: a systematic review and meta-analysis. Lancet Respir Med. 2016;4:116-28.

27. Rahman MA, Hann N, Wilson A, Mnatzaganian G, Worrall-Carter L. E-cigarettes and smoking cessation: evidence from a systematic review and meta-analysis. PLoS One. 2015;10:e0122544.

28. Skotsimara G, Antonopoulos AS, Oikonomou E, Siasos G, Ioakeimidis N, Tsalamandris S, et al. Cardiovascular effects of electronic cigarettes: a systematic review and meta-analysis. Eur J Prev Cardiol. 2019;26:1219-28.

29. Tzortzi A, Kapetanstrataki M, Evangelopoulou V, Beghrakis P. A systematic literature review of e-cigarette-related illness and injury: not just for the respirologist. Int J Environ Res Public Health. 2020;17:E2248 Updated review on the multidimensional safety issues related to electronic cigarettes.

30.• Fairchild AL, Lee JS, Bayer R, Curran J. E-cigarettes and the harmreduction continuum. N Engl J Med. 2018;378:216-9 Thoughtprovoking perspective on the promises and risks of using electronic cigarettes to foster cessation and abstinence from tobacco and smoking.

31. Murphy J, Gaca M, Lowe F, Minet E, Breheny D, Prasad K, et al. Assessing modified risk tobacco and nicotine products: description of the scientific framework and assessment of a closed modular electronic cigarette. Regul Toxicol Pharmacol. 2017;90:342-57.

32. Ganapathy V, Manyanga J, Brame L, McGuire D, Sadhasivam B, Floyd E, et al. Electronic cigarette aerosols suppress cellular antioxidant defenses and induce significant oxidative DNA damage. PLoS One. 2017;12:e0177780.

33. Espinoza-Derout J, Hasan KM, Shao XM, Jordan MC, Sims C, Lee DL, et al. Chronic intermittent electronic cigarette exposure induces cardiac dysfunction and atherosclerosis in apolipoprotein-E knockout mice. Am J Physiol Heart Circ Physiol. 2019;317:H445-59.

34. Kerr DMI, Brooksbank KJM, Taylor RG, Pinel K, Rios FJ, Touyz $\mathrm{RM}$, et al. Acute effects of electronic and tobacco cigarettes on vascular and respiratory function in healthy volunteers: a crossover study. J Hypertens. 2019;37:154-66.

35. MacDonald A, Middlekauff HR. Electronic cigarettes and cardiovascular health: what do we know so far? Vasc Health Risk Manag. 2019;15:159-74.
36. Smith KR, Hayat F, Andrews JF, Migaud ME, Gassman NR. Dihydroxyacetone exposure alters $\mathrm{NAD}(\mathrm{P}) \mathrm{H}$ and induces mitochondrial stress and autophagy in HEK293T cells. Chem Res Toxicol. 2019;32:1722-31.

37. Sciarretta S, Forte M, Frati G, Sadoshima J. New insights into the role of mTOR signaling in the cardiovascular system. Circ Res. 2018;122:489-505.

38. Cavarretta E, Frati G. MicroRNAs in coronary heart disease: ready to enter the clinical arena? Biomed Res Int. 2016;2016:2150763.

39. Biondi-Zoccai G, Romagnoli E, Agostoni P, Capodanno D, Castagno D, D'Ascenzo F, et al. Are propensity scores really superior to standard multivariable analysis? Contemp Clin Trials. 2011;32:731-40.

40. Biondi-Zoccai G, Carnevale R, Vitali M, Tritapepe L, Martinelli O, Macrina F, Bullen C, Peruzzi M, Cavarretta E, Marullo AG, Abbate A, Romagnoli E, Sciarretta S, Casati R, Visconti G, Versaci F, Frati G. A randomized trial comparing the acute coronary, systemic, and environmental effects of electronic vaping cigarettes versus heatnot-burn cigarettes in smokers of combustible cigarettes undergoing invasive coronary assessment: rationale and design of the SURVAPES 3 trial. Minerva Cardioangiol. 2020. https://doi.org/10. 23736/S0026-4725.20.05181-6.

41. Biondi-Zoccai G, editor. Network meta-analysis: evidence synthesis with mixed treatment comparison. Hauppauge: Nova Science; 2014.

42. Riva A, Corti A, Belcaro G, Cesarone MR, Dugall M, Vinciguerra $\mathrm{G}$, et al. Interaction study between antiplatelet agents, anticoagulants, diabetic therapy and a novel delivery form of quercetin. Minerva Cardioangiol. 2019;67:79-83.

43. Nagy Á, Kim JH, Jeong ME, Heo MH, Putzu A, Belletti A, et al. Non-vitamin K oral anticoagulants for coronary or peripheral artery disease: a systematic review and meta-analysis of mortality and major bleeding. Minerva Cardioangiol. 2019;67:477-86.

44. De Vecchis R, Paccone A, Di Maio M. Sacubitril/valsartan improves left ventricular longitudinal deformation in heart failure patients with reduced ejection fraction. Minerva Cardioangiol. 2019;67:456-63.

45. Chimenti I, Pagano F, Cavarretta E, Angelini F, Peruzzi M, Barretta A, et al. B-blockers treatment of cardiac surgery patients enhances isolation and improves phenotype of cardiosphere-derived cells. Sci Rep. 2016;6:36774.

46. Cottignoli V, Cavarretta E, Salvador L, Valfré C, Maras A. Morphological and chemical study of pathological deposits in human aortic and mitral valve stenosis: a biomineralogical contribution. Patholog Res Int. 2015;2015:342984.

47. Ratajczak A, Jankowski P, Strus P, Feleszko W. Heat not burn tobacco product-a new global trend: impact of heat-not-burn tobacco products on public health, a Systematic Review. Int J Environ Res Public Health. 2020;17:E409 Recent systematic review on heat-not-burn cigarettes, highlighting their similarities and differences in comparison with electronic vaping cigarettes.

Publisher's Note Springer Nature remains neutral with regard to jurisdictional claims in published maps and institutional affiliations. 